\title{
Cache pilferage in red-rumped agoutis (Dasyprocta leporina) (Rodentia)
}

\author{
Paulo R. GUIMARÃES Jr. \\ Programa de Pós-Graduação em Ecologia, Instituto de Biologia, \\ Universidade Estadual de Campinas (UNICAMP), CP 6109, 13083-970, Campinas, SP (Brazil) \\ Plant Phenology and Seed Dispersal Research Group, Departamento de Ecologia, \\ Universidade Estadual Paulista (UNESP), CP 199, 13506-900 Rio Claro, SP (Brazil) \\ Instituto de Biologia da Conservação (IBC), Campinas, SP (Brazil) \\ paulomiudo@uol.com.br
}

Bruno Z. GOMES

Programa de Pós-Graduação em Ecologia, Instituto de Biologia, Universidade Estadual de Campinas (UNICAMP), CP 6109, 13083-970, Campinas, SP (Brazil) Gerência Geral de Meio Ambiente, Companhia Siderúrgica Nacional (CSN), BR 393, Rodovia Lúcio Meira, Km 5001, Vila Santa Cecília, Volta Redonda, RJ (Brazil)

Yu Jie AHN Laboratory of Plant Systematics, School of Biological Sciences, Seoul National University, 151-742, Seoul (South Korea)

Mauro GALETTI Plant Phenology and Seed Dispersal Research Group, Departamento de Ecologia, Universidade Estadual Paulista (UNESP), CP 199, 13506-900 Rio Claro, SP (Brazil) Instituto de Biologia da Conservação (IBC), Campinas, SP (Brazil)

Guimarães Jr P. R., Gomes B. Z., Ahn Y. J., Galetti M. 2005. - Cache pilferage in red-rumped agoutis (Dasyprocta leporina) (Rodentia). Mammalia 69 (3-4): 431-434.

Food hoarding is the handling of food to conserve it for future use, and food hoarding animals have the capacity to control the availability of food in space and time (Smith \& Reichman 1984; Vanderwall 1990). The benefits derived from this control include an improved individual probability of survival during periods of food scarcity, optimized foraging and feeding, improved foraging for limited resources, and pro- vision of a continuous flow of food to offspring during the reproductive season (reviewed by Vanderwall 1990).

Inter- and intra-specific cache pilfering frequently reduces the cache resources of food hoarders, and there is evidence that the impact of cache pilfering can be impressive (Vanderwall \& Jenkins 2003). As a consequence, food hoarders have different behavioral strategies to minimize 
cache pilferage, including the distribution of food into several small caches (Daly et al. 1992), aggressive interaction with potential pilferers (Kilham 1958), the relocation of food to new caches (Vanderwall \& Joyner 1998), cache site selection (Vanderwall \& Balda 1981), cache concealment (James \& Verbeek 1983) and variation in cache depth (Vanderwall 1993). Cache protection is constrained by factors such as the impossibility of full-time defense, the need to spend energy and time in other activities, the cognitive and spatial constraints in cache management, the physical and chemical properties of cached food and the need for signals to make cache retrieval possible (reviewed by Vanderwall 1990). If cache pilfering affects the benefits of food hoarding, then understanding how cache pilfering occurs is a fundamental consideration.

Studies of the mechanisms and consequences of cache pilferage in rodents have suggested that pilfering is probably greater in the wet season (Vanderwall 2000) and depends on rodent olfactory abilities (Vanderwall et al. 2003). In addition, there is evidence that rodents scatter-hoard seeds (Daly et al. 1992) and change hoarding strategies (Preston \& Jacobs 2001) to reduce pilferage. Most of these studies have been done with rodent species from temperate regions. However, several Neotropical rodent species also cache food (Vanderwall 1990), but we still know little about how these animals locate and pilfer caches.

Red-rumped agoutis (Dasyprocta leporina L.: Dasyproctidae) are large terrestrial rodents that occur from neotropical savannas to evergreen forests. Agoutis are frugivorous and granivorous (Henry 1999) and, like the closely related Myoprocta, are key dispersers of large-seeded plant species (Forget 1992; Peres \& Baider 1997; Asquith et al. 1999). However, our knowledge of the foraging behavior in agoutis is very incipient (Smythe 1970, 1978; Guimarães et al. 2003; Silvius \& Fragoso 2003). The investigation of how environmental stimuli and sensorial mechanisms that promote cache location affect cache pilfering is essential for a correct understanding of rodent foraging ecology. Here, we investigated how cache depth and cache characteristics affect cache pilferage.

The experiments with red-rumped agoutis were done in September and October 1999 in the Bosque dos Jequitibás (hereafter BJ), a 10 ha forest fragment in an urban park in Campinas, São Paulo, Brazil. This forest is home to more than 60 tamed agoutis whose behavior can be observed at close range (Guimarães et al. 2003).

In the first experiment, we used artificial caches to test whether cache depth affects pilferage. Seeds of Hymenaea courbaril L. were collected and used for this experiment because agoutis usually cache these seeds (Asquith et al. 1999). The $45 \mathrm{H}$. courbaril seeds were buried individually to simulate caches at three cache depths $(\mathrm{n}=15$ for each cache depth): $-2 \mathrm{~cm}$ (minimum), $-4 \mathrm{~cm}$ (medium), and $-8 \mathrm{~cm}$ (maximum) (Guimarães, unpublished data). As there is evidence that agoutis usually cache seeds near trees (Smythe 1978), we randomly chose non- $H$. courbaril trees in a native area of the forest and cached each seed close ( $<5 \mathrm{~cm}$ away) to a tree. Only one seed was cached per tree. The number of seeds located by agoutis after $4 \mathrm{~h}$ was recorded and compared to the removal frequencies using a chi-square test.

In the second experiment, the importance of food scent cues in cache pilfering was examined. Hymenaea courbaril seeds were buried in four experimental groups ( $\mathrm{n}=30$ per group), all close to a non- $H$. courbaril tree ( $<5 \mathrm{~cm}$ away) and $4 \mathrm{~cm}$ deep: 1) $H$. courbaril seed, 2) $H$. courbaril seed wrapped in a $2 \times 2 \mathrm{~cm}$ plastic bag hermetically sealed to control specific seed scent, and 3) false cache with no seed to assess the influence of cache-related aspects. We used twigs to dig and bury the seeds in order to reduce bias related to our scent. In the fourth experimental group, one researcher crouched near a tree for $1 \mathrm{~min}$, as in the other experimental groups, but did not dug or touch the soil. This procedure was necessary to control for the effects of two processes that could invalidate the experiment, namely (1) random digging by agoutis and (2) observation of the researcher's actions by agoutis since at the study site agoutis are not afraid of humans and frequently approach humans to search for the 
remains of food. The number of artificial caches dug up by the agoutis after $4 \mathrm{~h}$ was recorded and the frequencies were compared with a chi-square test.

Cache depth did not affect the number of seeds pilfered after $4 \mathrm{~h}$. Most of the seeds ( $>80 \%$ ) in the experimental groups were removed by agoutis, and there were no significant differences among the frequencies of removal $\left(\chi^{2}\right.$ test, $\mathrm{P}>0.5)$. Agoutis dug but could not retrieve four seeds in 8-cm experimental caches. Twenty-four out of $30 \mathrm{H}$. courbaril seeds $(80 \%)$ were removed after $4 \mathrm{~h}$. A similar result was recorded for empty caches $(25$ out $30,83.3 \%)$ and for $H$. courbaril seeds wrapped in a plastic bag (25 out 30 , $83.3 \%)$. No crouch point was dug. There were no differences in the frequency of digging among the experimental groups $\left(\chi^{2}\right.$ test, $\left.\mathrm{P}>0.5\right)$.

The intensity of pilfering was not related to cache depth. Although some 8-cm experimental groups were located but not removed, the agoutis efficiently located nearly all of the "caches" in most of the experimental groups. Although there is evidence that for other rodents cache depth can reduce cache pilfering by conspecifics (Vanderwall 1990, 1993), this was not true for red-rumped agoutis, probably because agoutis bury their seeds close to the soil surface. Cached item features such as odor had no effect on the removal of $H$. courbaril seeds. Indeed, the only cue necessary for an agouti to dig was that the site had been dug. In a previous study, "true-food" caches were dug more frequently by $D$. punctata than false caches (Murie 1977), although false caches were also removed. We suggest that the discrepancy between this study and our results may be related to differences in the food items used in the two studies. The food items used by Murie (1977) (bananas, dry corn, and Astrocaryum nuts and shells) may have a stronger odor signal than the seeds of $H$. courbaril used here.

Cache pilfering based on cues related to digging may occur a considerable time (i.e. hours, or even days) after the caching, and may therefore be more difficult for the cache owner to prevent. The complex cache preparation used by dasyproctid rodents (see Smythe 1978) may be a strategy to reduce cache pilfering. However, cache-based cues probably do not last long on tropical forest floors and more long-term cache pilfering, if it occurs, may be related to other cues associated with the cached food or by direct random digging (sensu Vanderwall 1991). The presence of pulp in fleshy fruits could possibly enhance the odor signals that permit cache pilfering. Interestingly, agoutis rarely cache intact fleshy fruits and often eat or remove the pulp before caching the seeds/nuts (Guimarães, unpublished data). Similar behavior in other rodents may reduce the damage to seeds by fungi and pathogens (Vanderwall 1990). We suggest that removal of the fleshy pulp of large seeds may reduce cache pilfering by scent-oriented seed predators (agoutis, other rodents and peccaries).

\section{Acknowledgements}

The authors thank the Prefeitura Municipal de Campinas for permission to do fieldwork in the Bosque dos Jequitibás, E. Santos and P. Anselmo for logistical support, J.R. Trigo for help in designing the experiments, and C. Bottcher and J. José for help with the fieldwork. G. Machado, J. José, P. P. Coltri, R. Cogni and an anonymous reviewer provided valuable comments on earlier versions of the manuscript. S. Hyslop revised the English of the manuscript. PRG was supported by FAPESP (grant 99/00518-2) and MG was supported by FAPESP, the International Foundation for Science (IFS) and CNPq.

\section{REFERENCES}

Asquith N. M., Terborgh J., Arnold A. E. \& Riveros C. M. 1999. - The fruits the agouti ate: Hymenaea courbaril seed fate when its disperser is absent. Journal of Tropical Ecology 15 (2): 229-235.

Daly M., Jacobs L. F., Wilson M. I. \&. BEHRENDS P. R. 1992. - Scatter hoarding by kangaroo rats (Dipodomys merriami) and pilferage from their caches. Behavioral Ecology 3 (2): 102-111.

FORGET P. M. 1992. - Seed removal and seed fate in Gustavia superba (Lecythidaceae). Biotropica 24 (3): 408-414. 
Guimarāes P. R., José J., Galetti M. \& Trigo J. R. 2003. - Quinolizidine alkaloids in Ormosia arborea seeds inhibit predation but not caching by agoutis (Dasyprocta leporina). Journal of Chemical Ecology 29 (5): 1065-1072.

HENRY O. 1999. - Frugivory and the importance of seeds in the diet of the orange-rumped agouti (Dasyprocta leporina) in French Guiana. Journal of Tropical Ecology 15 (3): 291-300.

James P. C. \& Verbeek N. A. M. 1983. - The food storage behavior of the northwestern crow. Behaviour 85 (3-4): 276-291.

KILHAM L. 1958. - Territorial behavior of wintering red-headed woodpeckers. Wilson Bulletin 70 (4): 347-358.

MurIE J. O. 1977. - Cues used for cache-finding by agoutis (Dasyprocta punctata). Journal of Mammalogy 58 (1): 95-96.

Peres C. A. \& Baider C. 1997. - Seed dispersal, spatial distribution and population structure of Brazilnut trees (Bertholletia excelsa) in southeastern Amazonia. Journal of Tropical Ecology 13 (4): 595-616.

Preston S. D. \& Jacobs L. F. 2001. - Conspecific pilferage but not presence affects Merriam's kangaroo rat cache strategy. Behavioral Ecology 12 (5): 517-523.

Silvius K. M. \& Fragoso J. M. V. 2003. - Redrumped agouti (Dasyprocta leporina) home range use in an Amazonian forest: implications for the aggregated distribution of forest trees. Biotropica 35 (1): 74-83.

Smith C. C. \& Reichman O. J. 1984. - The evolution of food caching by birds and mammals. Annual Review of Ecology and Systematics 15 (1): 329-351.
SMYTHE N. 1970. - Relationships between fruiting seasons and seed dispersal methods in a neotropical forest. American Naturalist 104 (935): 25-35.

SMYTHE N. 1978. - The Natural History of the Central American Agouti (Dasyprocta punctata). Smithsonian Contribution to Zoology 274 (1): 1-52.

VanderWall S. B. 1990. - Food Hoarding in Animals. The University of Chicago Press, Chicago. $445 \mathrm{p}$.

VANDERWALl S. B. 1991. - Mechanisms of cache recovery by yellow chipmunks. Animal Behaviour 41 (5): 851-863.

VanderWall S. B. 1993. - A model of caching depth - implications for scatter hoarders and plant dispersal. American Naturalist 141 (2): 217-232.

VANDERWall S. B. 2000.- The influence of environmental conditions on cache recovery and cache pilferage by yellow pine chipmunks (Tamias amoenus) and deer mice (Peromyscus maniculatus). Behavioral Ecology 11 (5): 544-549.

VAnderWall S. B. \& Balda R. P. 1981. — Ecology and evolution of conifer-seed-catching corvids. Zeitschrift fur Tierpsychologie 56 (3): 217-242.

VanderWall S. B, Beck M. J., Briggs J. S., Roth J. K., Thayer T. C., Hollander J. L. \& ARMSTRONG J. M. 2003. - Interspecific variation in the olfactory abilities of granivorous rodents. Journal of Mammalogy 84 (2): 487-496.

VanderWall S. B. \& Jenkins S. B. 2003. - Reciprocal pilferage and the evolution of food-hoarding behavior. Behavioral Ecology 14 (5): 656-667.

Vander Wall S. B. \& JOYner J. W. 1998. Secondary dispersal by the wind of winged pine seeds across the ground surface. American Midland Naturalist 139 (2): 365-373. 